\title{
Working Environment of Nurses in Two District Hospitals
}

\author{
Ferdous Hasan ${ }^{1}$, Rubina Sultana², Lutfun $\mathrm{Nahar}^{3}$
}

\begin{abstract}
Context: The study was designed to see the working environment of nurses in two district hospitals.
\end{abstract}

Study design: Cross sectional, descriptive type of study.

Place and period of study: The study was carried out in National Institute of Preventive and Social Medicine (NIPSOM), Mohakhali, Dhaka from April to June, 2005.

Methods: A total of 60 (sixty) nurses were selected by systematic random sampling method. Two District Hospitals were selected by Purposive Sampling. Data was collected by: face- to-face interview using a questionnaire consisting of both close ended and open ended questions.

Results: Both positive and negative findings came out regarding working environment of the nurses.

Conclusion: Some suggestions came out to improve the working environment of the nurses.

Key words: Working environment, Nurses, District Hospitals.

\section{Introduction:}

Among the health service providers nurses are the personnel who remain in closest contact with the patients and interacts in many ways. They fill in the gaps between doctors- patients, hospital- patients, services- patients and so on by virtue of their position in the organization and the assignment given. They can minimize the anguish of diseases with their sympathized professional help \& have ample of time to cover social aspects of medical service.

More over nurses work for patients who are in obvious physical discomfort of various intensity and mentally stressed and so are their relatives and attendants. So, in one hand we never know how such a group will react in a critical situation and on the other hand how the nurses will response to the situation. A healthy person has many problems, demands \& desires and unending thirst for achievements \& success and ready to try for years together. Now, in contrast to healthy one, a sick person has only one problem that is his disease and his only thirst

1. Assistant Professor, Dept of Community Medicine, Sylhet Women's Medical College, Sylhet

2. Associate Professor, Dept of Anatomy, Sylhet Women's Medical College, Sylhet

3. Faculty member, College of Medicine, King Fahad Medical College, Riyadh, K.S.A.

Correspondence: Dr. Md. Ferdous Hasan is for cure but not ready to tolerate any delay or discrepancy. Knowing all these and many other factors and situations nurses are to deliver their services in the best possible way.

To perform this artistic task of nursing the diseased, nurses must have good physical and best mental capability. In order to keep the nurses in a sound mental condition \& motivated towards the fulfillment of patient needs, a good working environment is essential, and could be considered as primary requirement. So, the present study was designed to identify the factors with which they are satisfied and dissatisfied as well and to find out the ways to provide a good positive working environment.

\section{Materials and Methods:}

A cross sectional descriptive type of study was conducted in Narayangong Sadar Hospital (NSH) and Adhunic Sadar Hospital, Kishoregong (ASHK) among the nurses (excepting supervisors) with the aim to see their working environment. Both the hospitals for study were selected by purposive sampling. Reason for that is NSH is situated near to Dhaka City where plenty of health service facilities available and ASHK is the only hospital in that area that could make a big difference in patient load. A total of 60 (sixty) nurses were selected by systematic random sampling method, 30 from each 
of the hospitals but 2 in ASHK and 01 in NSH were not available at the time of data collection. So, the actual sample size was 57 . The duration of study period was from April, 2005 to June, 2005. Data were analysed in the National Institute of Preventive and Social Medicine (NIPSOM), Mohakhali, Dhaka. The information and opinions from the respondents were collected by the researcher himself by faceto-face interview using a questionnaire consisting of both close ended and open ended questions.

Result:

Bed strength, Patient load and staffing:

\section{Narayanganj Sadar Hospital :}

This hospital was established with 31 beds as Thana Health Complex. Thereafter, this hospital was modernized and increased its bed strength to 100 . At present, the number of nurses is 56 ; opined as adequate, so the number of beds in relation to the patients load ranging from 70 - 90, although wards and cabins of some departments are situated in different floors making difficult to cover with the same group of nurses assigned for both. There is no dormitory for nurses. No guard at all is appointed and is rather surprising because the area is known as 'crime zone'. Occasional threats to the nurses

Table-I

Distribution of the respondents by their opinion regarding working environment $N=57$

\begin{tabular}{lcccccc}
\hline Key Variables & \multicolumn{5}{c}{ Opinion } & Total \\
\cline { 2 - 6 } & $\begin{array}{c}\text { Highly } \\
\text { satisfied }\end{array}$ & Satisfied & Uncertain & Dissatisfied & $\begin{array}{c}\text { Poorly } \\
\text { Dissatisfied }\end{array}$ \\
\hline Freedom in daily activity & $0(0 \%)$ & $56(98 \%)$ & $1(2 \%)$ & $0(0 \%)$ & $0(0 \%)$ & $57(100 \%)$ \\
Getting respect from society & $6(10.5 \%)$ & $44(77 \%)$ & $3(5.5 \%)$ & $4(7 \%)$ & $0(0 \%)$ & $57(100 \%)$ \\
Doctor -nurses relationship & $19(33.5 \%)$ & $36(63 \%)$ & $2(3.5 \%)$ & $0(0 \%)$ & $0(0 \%)$ & $57(100 \%)$ \\
Workload & $2(3.5 \%)$ & $21(37 \%)$ & $4(7 \%)$ & $16(28 \%)$ & $14(24.5 \%)$ & $57(100 \%)$ \\
Co-operation from colleagues & $38(67 \%)$ & $17(29.5 \%)$ & $2(3.5)$ & $0(0 \%)$ & $0(0 \%)$ & $57(100 \%)$ \\
Number of subordinate staff & $1(2 \%)$ & $1(2 \%)$ & $1(2 \%)$ & $27(47 \%)$ & $27(47 \%)$ & $57(100 \%)$ \\
\hline
\end{tabular}

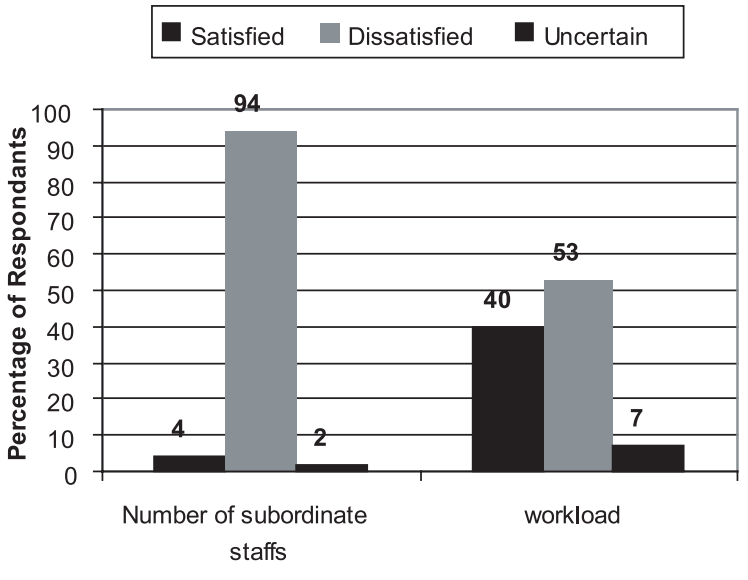

Aspects of Working Environment

Fig.-1: Showing distribution of respondents regarding different aspects of working environment

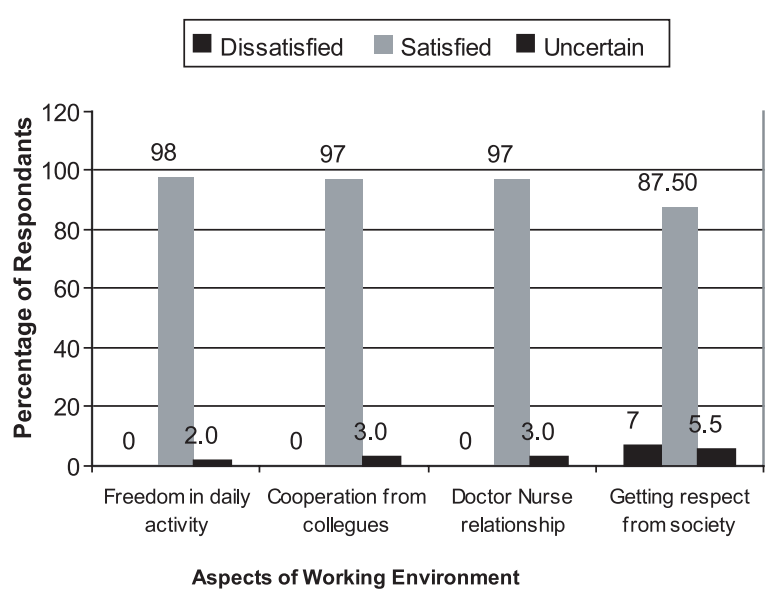

Fig.-2: Showing distribution of respondents regarding different aspects of working environment 
and other workers at nights are common, and even at day times. Electrician and Plumber are not appointed. Number of MLSS and cleaners found insufficient

\section{Adhunik Sadar Hospital, Kishoreganj:}

This hospital was established with 50 beds. Thereafter it was modernized and named Adhunik Sadar Hospital, Kishoregong and the number of beds increased to 100 . The average number of admitted patients always exceeds 200 with a highest number of 269 patients as recorded in the month of August, 2004. The number of nurses is inadequate; only 44. Number of MLSS and cleaners is negligible \& some outsider found to control visitors at the gate. It has a doctor's quarter and a dormitory for the nurses in the hospital compound.

The present study was designed to see the working environment of nurses in two district hospitals of Bangladesh. Because the nursing work environment not only impacts nurses and also impact patients ${ }^{1,2,3}$. Unhealthy nursing work environments have been demonstrated to contribute to nursing turnover. Nursing turnover destabilizes the nursing workforce and coupled with the nursing shortage, leads to short-staffing and use of contract labor, both which have been associated with threats to patient's safety and patient's satisfaction with their health care ${ }^{4}$. Martha also stated that the nursing shortage is negatively affecting the quality, effectiveness, and timeliness of patient care, which warrants a transformation of the nursing work environment ${ }^{4}$. Agency for Healthcare Research and Quality of the US Department of Health and Human Services also stated that the work environment for nurses that likely have an impact on patient safety ${ }^{5}$. Marlene mentioned that Safe patient care is directly and positively linked to the quality of staff nurses' work environments. Healthy work environments are empirically linked to patients' satisfaction and to retention, reduced turnover, increased attraction, job satisfaction, and lower degree of job stress and burnout among nurses ${ }^{6}$. Increasingly, professional organizations and state and national commissions are challenging nurses, hospital administrators, and health-care organizations to improve the practice environment for staff nurses in order to reap the benefits, particularly patients' safety and nurses' job satisfaction and retention 1,2,5-8,10-12. Achieving such improvement requires a baseline reading of staff nurses' perceptions of the health of the work environment, implementation of improvement strategies, and confirmation of the success or failure of the strategies by clinical nurses at the front line ${ }^{6}$.

In the present study six key variables were selected related to working environment. These are ranked in relation to the percentage of highly satisfied and satisfied respondents. From highest to lowest arefreedom in daily activity $98.25 \%(56)$, getting respect from society $87.71 \%(50)$, getting cooperation from colleagues $96.5 \%(55)$, Doctor-nurse relationship $96.5 \%(55)$, workload $40.35 \%(23)$ and number of subordinate staff $3.5 \%(2)$. The results were satisfactory in all aspects excepting in regard to the number of subordinate staffs and workload. Though patients load is more than double in ASHK than in NSH and the number of nurse in the former hospital is only three fourth of the later one. So, there is some discrepancy in staffing norm that needs to be minimized. Linda identified ten variables for working environment of nurses. She mentioned reasonable work load is the one of the variable of good working environment ${ }^{\text {. }}$.

Corley mentioned that a larger percent $(25 \%)$ of nurses had left a position in the past due to moral distress compared to $13 \%$ in 1995 . Their highest level of moral distress was due to inadequate staffing $^{8}$. Roseline mentioned that in general, nurses had better opinion of doctors' work than doctors had about nurses' work. Nurse-doctor working relationships were statistically significantly affected by staff shortages, disregard for one's profession, and hospital management and government policies ${ }^{9}$. In this study nurses were positively commented about the relationship between doctors and nurses.

Leonard mentioned that doctors can do much to improve the nature of their relationship with nursing colleagues by professional respect, common sense, involving awareness, act and sensitivity ${ }^{10}$.

Another important finding came out from this study regarding work place safety. It was revealed that there was no guard in NSH and nurses face some security problems especially at nights. Linda stated that work place safety also affects the nursing 
environment ${ }^{7}$. So, improving healthy working environment of nurses work place safety need to be ensured.

Highest degree of dissatisfaction revealed by the nurses in respect of number of supporting staff that is cleaners and MLSS. They are not only needed for the nurses' activity but also for the maintenance of cleanliness and for essentially needed hospital hygiene; a prerequisite to prevent cross infection. It should be worked out to recruit adequate supporting staffs. All district hospitals are not to bear same patients load. So, information regarding the patients load in different hospitals should be recorded and staffed accordingly.

\section{References:}

1. Aiken, Clarke, Sloane, Sochalski \&Siber, 2002; http://stti.confex.com/stti/congrs07/ techprogram/paper_34842.htm. [Accessed on 23.04.2010].

2. Larrabee, Ostrow, Withrow, Janney, Hobbs \& Burant, 2004 http://stti.confex.com/stti/ congrs07/techprogram/paper_34842.htm. [Accessed on 23.04.2010].

3. Vahey \& Aiken, Sloane, Clarke, Vargus, 2004 http://stti.confex.com/stti/congrs07/ techprogram/paper_34842.htm. [Accessed on 24.04.2010].

4. Martha M , Susan G J. Stephanie T Mary, Steve S Helen M, Clair J. Creating a Positive Work Environment: Implementation of the Nurse-Friendly Hospital Criteria. The Journal of Nursing Administration: February 2009; 39(2): 64-70. http://journals.Iww.com/ jonajournal/Abstract/2009/02000/ Creating_a_Positive_Work. [Accessed on 20.04.2010].

5. Browse History Work Environment for Nurses and Patient Safety.The Institute of Medicine of national academies - the Agency for Healthcare Research and Quality of the US. Department of Health and Human Services. http://www.iom.edu/Activities/Quality/ nurseandpatientsafety.aspx [Accessed on 23.04.2010].
6. Marlene K., Claudia S. Confirmation of a Healthy Work Environment. Critical Care Nurse. 2008;28: 56-63.http://ccn.aacnjournals. org/cgi/content/full/28/2/56. [Accessed on 23.04.2010].

7. Linda McGillis Hall, RN, PhD .Quality Work Environment: For Nurse and Patient Safety. 2005 http://www.pohly.com/books/qualitywork .html. [Accessed on 23.04.2010].

8. Corley MC, Jacobs M, Minick P, Elswick RK; Academy for Health Services Research and Health Policy. Meeting. Abstr Acad Health Serv Res Health Policy Meet. 2000; 17: UNKNOWN. http://stti.confex.com/stti/ congrs07/techprogram/paper_34842.htm. [Accessed on 23.03.2010].

9. Roseline I Ogbimi and Clement AAdebamowo Questionnaire survey of working relationships between nurses and doctors in University Teaching Hospitals in Southern Nigeria. Institute Of Public Administration and Extension Services, University of Benin, Benin-City, Nigeria.West African Bioethics Training Program, Division of Oncology, Department of Surgery, College of Medicine, University of Ibadan, University College Hospital, Ibadan, Oyo State, Nigeria. February 21, 2006. [Accessed on 23.04.2010].

10. Leonard Fagin and Antony Garelick. The doctor-nurse relationship The North East London Mental Health Trust (South Forest Centre, 21 Thorne Close, London E11 4HU, UK. E-mail: Leonard.Fagin@nelmht.nhs.uk).

11. Aiken et al, 2002 http://stti.confex.com/stti/ congrs07/techprogram/paper_34842.htm. [Accessed on 23.04.2010].

12. Caroline E. Brown, DEd, CNS, WHNP and Lauren Hunter, Ph, D, CNM, WHNP. Influence of the Nursing Work Environment on Nursing Outcomes.Nursing, San Diego State University, San Diego, CA, USA.http:// stti.confex.com/stti/congrs07/techprogram/ paper_34842.htm. [Accessed on 23.04.2010]. 